\title{
Loop type cecal volvulus: Multidetector computed tomography (MDCT) findings
}

Nancy Sánchez-Rubio, Pilar Redondo-Buil, Ana M. ${ }^{a}$ Benítez-Vázquez, Amador Prieto-Fernández and Alicia Mesa-Álvarez

Service of Radiodiagnosis. Hospital Universitario Central de Asturias. Oviedo, Asturias. Spain

\section{CASE REPORT}

A 67-year-old woman presented in the emergency room with abdominal pain for 2 hours. Physical examination showed abdominal distension and diffuse pain without signs of peritoneal irritation.

A plain abdominal radiography showed distension of cecum located ectopically in the left upper quadrant, with little aeration of the distal colon. Given these findings, an intravenous contrast enhanced multidetector computed tomography (MDCT) was performed (Figs. 1-4). The cecum was markedly enlarged and dilated, twisted and inverted, occupying the left hypochondrium. The terminal ileum was twisted also. These results were very suggestive of loop type cecal volvulus.

\section{DISCUSSION}

Cecal volvulus is an uncommon condition caused by the turning round of the cecum around its own mesenteric axis. A $360^{\circ}$ rotation of the mesenteric pedicle of the ileo-colic artery is generally produced. This causes strangulation with occlusion of the two intestinal edges and risk of vascular damage.

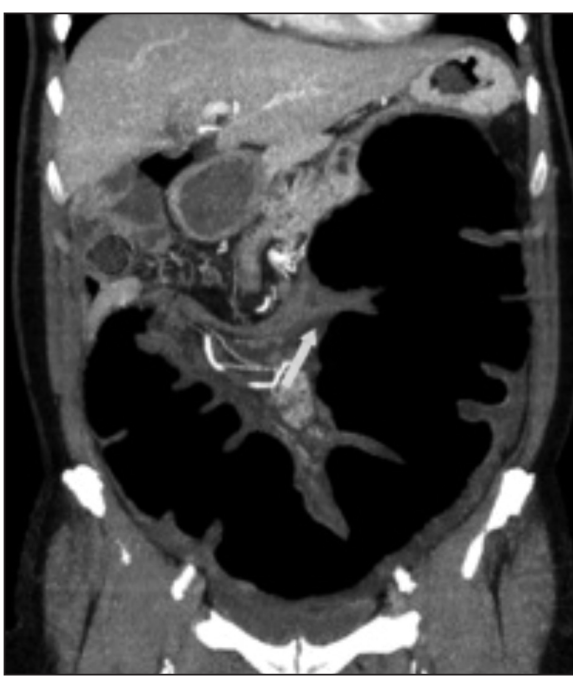

Fig. 1. MDCT reconstruction in coronal plane. The cecum was markedly enlarged, dilated, twisted and inverted occupying the left upper quadrant of the abdomen, together with the terminal ileum (yellow arrow).

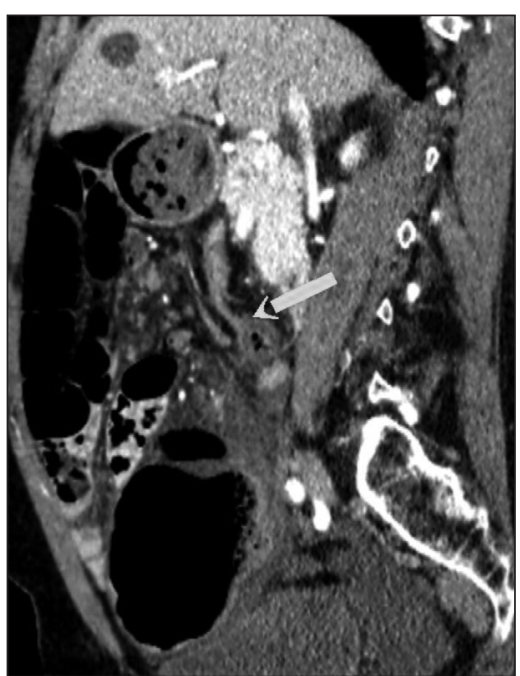

Fig. 2. MDCT reconstruction in sagittal plane. Bird's beak sign (yellow arrow) was identified. This depicted an abrupt transition between the twisted segment, which was collapsed, and the obstructed segment, which was dilated.

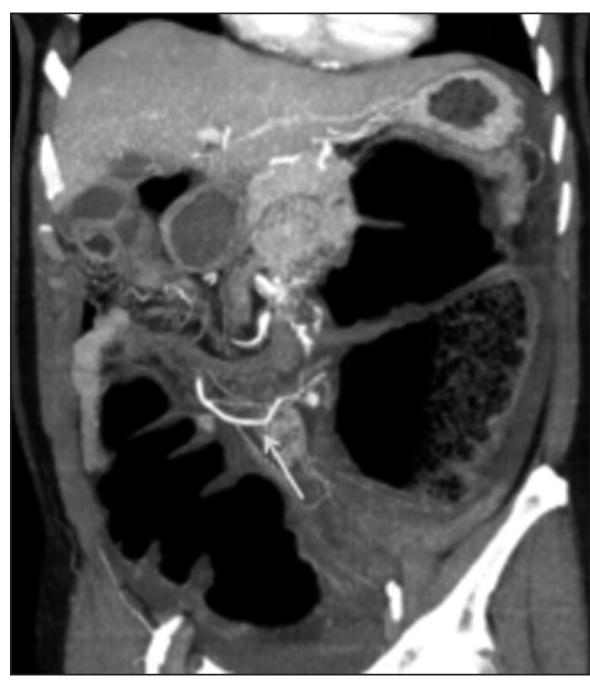

Fig. 3. MDCT reconstruction in coronal plane. Whirl sign. Torsion of the mesentery was recognized, with a spin of ileo-colic artery (yellow arrow) into the left upper quadrant, accompanying the cecum and the terminal ileum. 
Cecal volvulus can be produced by axial torsion of the cecum, by collapse into the ascending colon (cecal bascule), or by turning and reversing its position occupying the left upper quadrant (cecum loop twist or loop type). The third type of cecal volvulus is presented here. Differentiation between the three subtypes of cecal volvulus is not important from a clinical point of view, as its presentation and treatment are similar. However, radiographic appearances are different, and recognition of these differences is important for diagnosis.

The main signs that can be found on MDCT are:

- The cecum is located in the left upper quadrant and markedly distended $(>10 \mathrm{~cm})$, which has a specificity approaching $100 \%$.

- Bird's beak sign: Abrupt transition between the collapsed, twisted segment and the dilated, obstructed segment.

- Whirl sign: Torsion of the mesentery and intestinal loops along the axis of rotation.

\section{RECOMMENDED REFERENCES}

1. Moore CJ, Corl FM, Fishman EK. CT of Cecal volvulus: Untraveling the image. AJR Am J Roentgenol 2001;177:95-8.

2. Peterson CM, Anderson JS, Hara AK, Carenza JW, Menias CO. Volvulus of the gastrointestinal tract: Appearances at multimodality imaging. Radiographics 2009;29:1281-93.

3. Codina Cazador A, Farres Coll R, Olivet Pujol F, Pujadas de Palol M, Martín Grillo A, Gomez Romeu N, et al. Vólvulo de colon y recidiva del vólvulo: qué debemos hacer. Cir Esp 2011;89:237-42.

4. Rosenblat JM, Rozenblit AM, Wolf EL, DuBrow RA, Den EI, Levsky JM. Findings of cecal volvulus at CT. Radiology 2010;256:169-75.

5. Echenique Elizondo M, Amondaraín Arratíbel JA. Vólvulos de intestino grueso. Rev Esp Enferm Dig 2002;94:201-5. 